\title{
Link the world's best investigators
}

\section{Nurturing small groups of leading researchers - especially young scientists - is the way to break intellectual ground, says Alan Bernstein.}

W hen the molecular-biology revolution began in the 1950 s, biochemist Erwin Chargaff observed that the physicists, chemists and geneticists involved were "practising biochemistry without a licence". He didn't recognize that this small group of young innovators was forging an entirely new approach to biology.

Many challenges facing humanity, from chronic disease to climate change, demand a multidisciplinary perspective and fresh thinking - as well as a global approach. Yet few seasoned researchers venture beyond their scientific fields, campuses or national funding programmes. The obstacles are even greater for young scientists, whose creativity is constrained within large teams dominated by senior investigators, and whose prospects for funding and positions are dwindling.

As I approach the end of my first year as president of the Canadian Institute for Advanced Research (CIFAR), I have been reflecting on how best to support transformative advances in science. As globalization and the pace and scale of research increase, different sorts of institutions and funding models are needed. As a virtual global network, CIFAR offers one vision for supporting exchanges across borders and disciplines. But more needs to be done to enable talented young scientists to pursue original, multidisciplinary work.

\section{GLOBAL COLLABORATION}

For three decades, CIFAR has brought together small groups of outstanding researchers from varied fields to focus on important scientific questions. Rather than replicating the university campus, as other advanced institutes do, CIFAR functions as a virtual academy. From its headquarters in Toronto, CIFAR's 12 networks - which cover topics from human health and quantum materials to economics and sustainability — link almost 400 fellows and advisers from 103 institutions in 16 countries (see 'Four themes'). Landmark studies so far include Why Are Some People Healthy and Others Not? ${ }^{1}$ and Why Nations Fail ${ }^{2}$.

CIFAR is not a granting agency, but convenes meetings for its global programmes, typically twice a year. With an operating budget in 2013 of Can $\$ 17$ million (US\$17 million), CIFAR is funded by federal and provincial Canadian governments, individuals and the private sector.

The institute's recipe for success has three key ingredients: framing the right question,

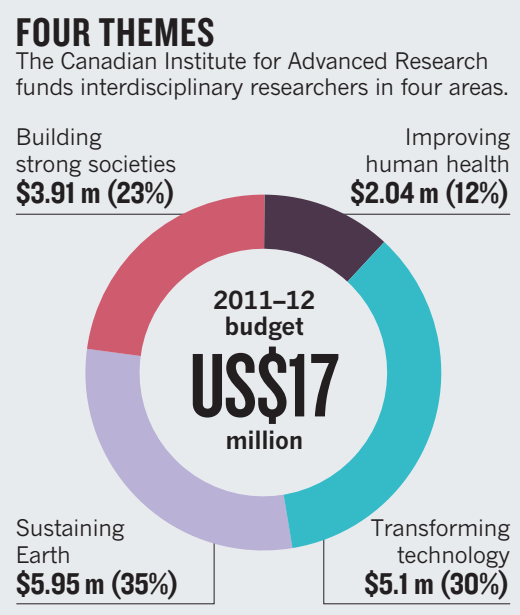

identifying the right researchers and leader, and supporting a network for long enough to overcome disciplinary and cultural barriers.

The compelling questions that interest CIFAR should presage a new field of enquiry, require multiple perspectives to answer and have enough appeal to bond a diverse group. The question of how early social experiences affect an individual's life-long physical and mental health and well-being, for example, is the focus of our Child \& Brain Development programme ${ }^{3}$. This year, CIFAR will launch its first Global Call for Ideas, inviting the Canadian and world research community to propose new questions on global challenges.

Each programme is overseen by an external advisory committee of 3-5 distinguished investigators who help to select members and direct the research. Programmes are reviewed every 5 years by an external panel on the basis of scientific excellence, synergy and impact. Programmes may be terminated, extended for a further 5 years, or renewed with different leadership or in a new direction.

The choice of members is crucial. Scientific excellence is a prerequisite, and 'talent attracts talent'. The programmes' disciplinary and geographic diversity make it essential that members have exemplary communication skills. Leadership also matters, so programme directors must have high standing and experience of running their own groups. To develop novel ideas, they also need listening skills and the ability to synthesize viewpoints.

It takes time to find common ground, so CIFAR typically supports programmes for 10-15 years. Deep dialogue requires trust, which is built through face-to-face exchanges. The use of small groups (15-20 people) retains intimacy while encouraging robust discussions and risk taking.

There are no requirements for how much $\underset{\mathrm{u}}{\mathrm{u}}$ time each fellow must devote to the pro- o gramme; collaborations arise naturally. Most fellows say that their involvement changes the long-term direction of their research.

Some might argue that the hand-picking of fellows is elitist, but I believe that it provides an opportunity for the best to succeed. On the advice of the programme director and the advisory committee, fellows are approved by the president, with appointments monitored closely by CIFAR's board of directors to avoid bias. Nevertheless, the involvement of one group still needs to be strengthened: that of young investigators.

\section{THE NEXT GENERATION}

Young investigators are crucial to the future of research, especially at a time of profound technological change. Computational biology, for example, is largely driven by emerging scientists. But young scientists face many hurdles, from low grant success rates to a dearth of academic positions and the difficulty of developing autonomy within large teams. Those in the developing world are further hindered by scarce resources, remoteness, and heavy teaching and administrative loads ${ }^{4}$.

Although CIFAR has brought 24 outstanding young researchers into its existing programmes, we recognize that this is not enough. In February, we launched the CIFAR Global Academy, an initiative that will help emerging researchers to develop their careers. It will include visits and exchanges, meetings and programmes at the interface between research, policy and practice.

We need to increase the world's capacity to collaborate and to nurture the next generation of research leaders. We hope that other organizations will work with us to explore new partnerships and models of interaction across disciplines, nations and generations.

Alan Bernstein is president of the Canadian Institute for Advanced Research, Toronto, Ontario M5G 1Z8, Canada. e-mail:abernstein@cifar.ca

1. Evans, R. G., Barer, M. L. \& Marmor, T. R. Why Are Some People Healthy and Others Not? (Walter de Gruyter, 1994).

2. Acemoglu, D. \& Robinson, J. A. Why Nations Fail (CROWN Business, 2012).

3. Hertzman, C. Proc. Natl Acad. Sci. USA 109 (suppl. 2), 17160-17167 (2012).

4. Barouch, D. H. et al. Nature Precedings http:// dx.doi.org/10.1038/npre.2010.4800.2 (2010). 